\title{
Predictive factors of success at the French National Ranking Examination (NRE): a retrospective study of the student performance from a French medical school
}

\author{
Martin Lhuaire ${ }^{1,2^{*}}$ D, Moustapha Dramé ${ }^{3}$, Mikael Hivelin ${ }^{2}$, Thomas Levasseur ${ }^{4}$, Quentin Maestraggi ${ }^{5}$, \\ Vincent Hunsinger ${ }^{2}$, Peter Abrahams ${ }^{6}$, Laurent Lantieri ${ }^{2}$ and Daniele Sommacale ${ }^{1}$
}

\begin{abstract}
Background: The national ranking examination (NRE) marks the end of the second cycle (6th university year) of French medical studies and ranks students allowing them to choose their specialty and city of residency. We studied the potential predictive factors of success at the 2015 NRE by students attending a French School of Medicine.

Methods: From March 2016 to March 2017, a retrospective study of factors associated with the 2015 NRE success was conducted and enrolled 242 students who attended their sixth year at the school of medicine of Reims. Demographic and academic data collected by a home-made survey was studied using univariate and then multivariate analysis by generalized linear regression with a threshold of $p<0.05$ deemed significant.

Results: The factors independently associated with a better ranking at the NRE were the motivation for the preparation of the NRE (gain of $3327 \pm 527$ places, $p<0.0001$ ); to have participated in the NRE white test organized by la Revue du Praticien in November 2014 (gain of $869 \pm 426$ places, $p<0.04$ ), to have participated in the NRE white test organized by la conférence Hippocrate in March 2015 (+ 613 places $\pm 297, p<0.04$ ). The factors independently associated with poor NRE ranking were repeating the first year (loss of 1410 places \pm 286 , $p<0.0001$ ), repeating a year during university course (loss of 1092 places $\pm 385, p<0.005$ ), attendance of hospital internships in 6th year (loss of 706 places $\pm 298, p<0.02$ ).

Conclusions: The student motivation and their white tests completion were significantly associated with success at the NRE. Conversely, repeating a university year during their course and attendance of 6th year hospital internships were associated with a lower ranking.
\end{abstract}

Keywords: National ranking examination, Prognostic study, Predictive factors of success, Medical pedagogy

\footnotetext{
* Correspondence: martin.Ihuaire@etu.parisdescartes.fr

'Department of General and Digestive Surgery, Hôpital Robert Debré, Centre Hospitalier Universitaire de Reims, Université de Reims Champagne-Ardenne, Avenue du Général Koenig, 51092 Reims, France

${ }^{2}$ Department of Plastic, Reconstructive and Aesthetic Surgery, Hôpital

Européen Georges Pompidou, Assistance Publique des Hôpitaux de Paris,

Université Paris Descartes, Paris, France

Full list of author information is available at the end of the article
}

(c) The Author(s). 2019 Open Access This article is distributed under the terms of the Creative Commons Attribution 4.0 International License (http://creativecommons.org/licenses/by/4.0/), which permits unrestricted use, distribution, and reproduction in any medium, provided you give appropriate credit to the original author(s) and the source, provide a link to the Creative Commons license, and indicate if changes were made. The Creative Commons Public Domain Dedication waiver (http://creativecommons.org/publicdomain/zero/1.0/) applies to the data made available in this article, unless otherwise stated. 


\section{Background}

The national ranking examination (NRE) marks the end of the second cycle of french medical studies. All french medical students must participate in the examination at the end of the 6th year of their university medical curriculum before beginning their residency (third cycle of french medical studies). Following this very selective examination (ranking of 8908 candidates in 2015), students are ranked according to their performance. The rank obtained is decisive for the student's professional career, since it allows them to choose the specialty and the city in which they will complete the residency (M.D degree) $[1,2]$. The main objective of the NRE is to rank medical students, but it also allows ranking right across all 35 french medical schools on the basis of their students performances at this examination [3, 4]. Since 2010, a yearly statistical analysis of the results of the NRE gives the ranking of French medical schools, which remains substantially identical from year to year [4-9]. In this context, it seems obvious that a given student, regardless of their potential for personal success, does not have the same probability of success at NRE dependent on their medical school of attendance. There are indeed disparities in terms of quality of education and therefore a real inequality of opportunity depending on the geographical location of medical students in France. Indeed, Karila et al., had demonstrated in 2011 that attending medical school in Île-de-France (Paris) was independently and significantly associated with a better ranking at the NRE [10]. Rabineau and Dhainaut in 2010 reinforces this unequal picture by demonstrating that there is a triple correlation between the percentage of students ranked in the top 1000 at the NRE, the research activity of university hospital practitioners and the ratio of university hospital practitioners relative to the number of students from different medical schools [3]. Every year amongst, the medical school of Reims is invariably ranked the lowest in France in terms of success of its students at the NRE [4-9]. In this sense, it seemed interesting to determine whether the predictive factors for NRE success previously described in the literature were influenced by the student's school of medicine of attendance. Lastly, it seemed only sensible to identify objectively the existence of predictive factors of success and to analyze their impact on an individual level.

The objective of this study was to determine the predictive factors of success at the $2015 \mathrm{NRE}$ of the 6th year medical students attending the medical school of Reims.

\section{Methods}

\section{Study design}

Between March 2016 and March 2017, a retrospective study of factors associated with the 2015 NRE success was carried out and enrolled 242 students who attended their sixth year at the Reims medical school.

\section{Data management}

Demographic, academic and results data of the white test examinations organized by the private NRE training conferences (Conférence Hermès, SASU, 11 rue de la vistule, Paris; Hippocrate-ECN, Faculté Dauphine, Place du Maréchal de Lattre de Tassigny, Paris; Conf-raphael, 10 rue Castex, Paris; Med XL / Conf +, 15 Rue Saint Bernard, Paris; Conférence Khalifa, Établissement d'enseignement supérieur libre, 134 Rue de Grenelle, Paris) were collected respectively according to the data published publicly by the school of medicine, by the Official Journal of the French Republic and finally by the private training organizations on their respective websites. Data not publicly available was collected using a self-survey written in Word format (Microsoft, Redmond, USA) and delivered by email with the study's letter of intent to inform the students concerned about the nature and purpose of the study, but also the confidential and anonymous treatment of all data collected, the prior declaration to the french national commission of informatics and liberties (CNIL) and finally the possibility left to everyone to opt out of the study. The survey consisted of 10 items (see Additional file 1) including a 3-items Likert-scale to measure the student motivation. Data collected in the framework of the study were in accordance to the French laws and subject to a declaration and approved by the CNIL ( $\left.{ }^{\circ} 1907841 v 0\right)$.

\section{Statistical analysis}

Descriptive analysis of quantitative variables was performed using means and standard deviations. Descriptive analysis of categorical variables was performed using enrollments and their percentages. In univariate analysis the quantitative variables were studied by the Pearson correlation coefficient and for the categorical variables by comparison of the mean by the Student or KruskalWallis test according to the conditions of application. Statistically significant variables with a threshold of $p<0.05$ in univariate analysis were used for multivariate analysis using a generalized linear regression whose results are expressed in $\beta \pm$ standard error (SE). Statistical analyzes were performed with SAS software version 9.4 (SAS Insitute, Inc., Cary, NC, USA) and the threshold of $p<0.05$ was deemed significant.

\section{Results}

\section{Descriptive results}

A total of 242 students were enrolled in the 6th year during the 2014-2015 academic year (Fig. 1). The mean age at the NRE was $25 \pm 1.5$ years (range: $22-34$ years) (Tables 1, 2 and 3). This cohort was predominantly female $(n=141,58 \%)$ for 101 male $(42 \%)$. Out of these 242 students, 236 (98\%) participated in the 2015 NRE (Fig. 1). The mean ranking of the Reims students at 


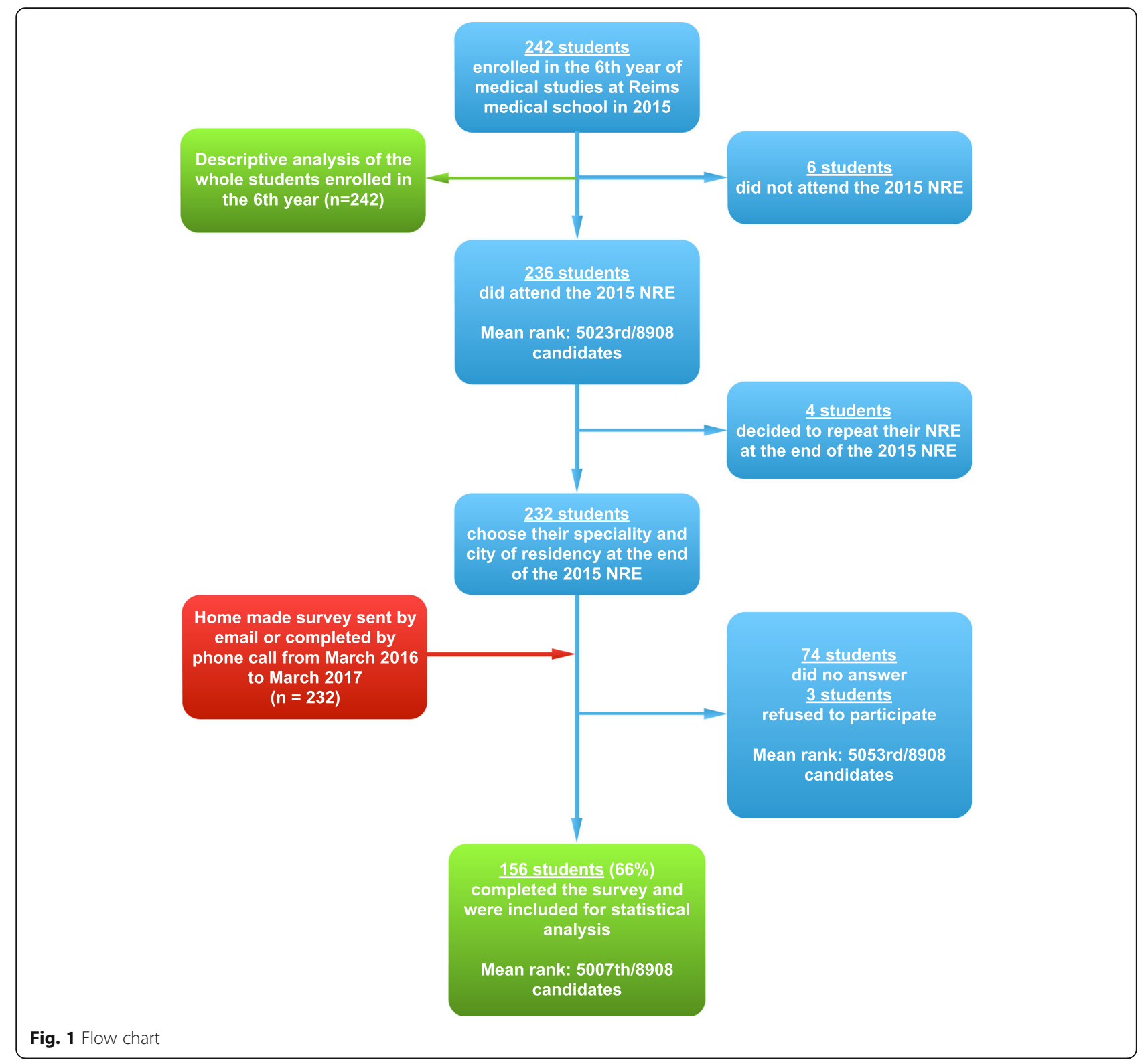

2015 NRE was 5023rd/8908 candidates (Limits: 12th 8743rd, SD: \pm 2435 places). Ten students $(4 \%)$ chose to repeat their 6th year at the end of the 2015 NRE in order to retake the examination in 2016, among them 4 students completed the 2015 NRE and were ranked (Fig. 1). The average of their rankings was 5859th / 8908 candidates. The remaining 6 students decided to repeat during the year and did not participate at the 2015 NRE and therefore were not ranked (Tables 1 and 2). Results of the univariate analysis were presented in Tables 1, 2 and 3.

\section{Results of the multivariate analysis}

The factors independently associated with a better ranking at the NRE were the motivation for the preparation of the examination (gain of $3327 \pm 527$ places, $p<0.0001$ ), to have participated in the NRE white test organized by La Revue du Praticien in November 2014 (gain of $869 \pm 425$ places, $p<0.04$ ), to have participated in the NRE white examination organized by the Hippocrate conference in March 2015 (gain of $613 \pm 297$ places, $\mathrm{p}<0.04$ ). The factors independently associated with poor NRE ranking were repetition in their first year (loss of $1410 \pm 286$ places, $\mathrm{p}<0.0001$ ), repetition during their university course (loss of $1092 \pm 385$ places, $p<0.005$ ), attendance of hospital internships in their 6th year (loss of $706 \pm 298$ places, $p<0.02$ ) (Table 4 and Fig. 2). Student results, choice of specialty and city after the 2015 NRE are presented in Figs. 3 and 4. 
Table 1 Description of the categorical variables of the cohort $(n=242)$ and univariate analysis of the predictive factors associated with a better ranking of the Reims students at the 2015 NRE

\begin{tabular}{|c|c|c|c|}
\hline Variables & $\mathrm{n}(\%)$ & Mean rank ( \pm SD) & $p$ \\
\hline$\overline{\text { Population }^{1}}$ & $236(98 \%)$ & & \\
\hline Gender & & & 0.77 \\
\hline Female & $138(58 \%)$ & $5062( \pm 2261)$ & \\
\hline Male & $98(42 \%)$ & $4969( \pm 2674)$ & \\
\hline Answered survey & & & 0.89 \\
\hline Yes & $156(66 \%)$ & $5007( \pm 2444)$ & \\
\hline No & $80(34 \%)$ & $5053( \pm 2435)$ & \\
\hline Decided to repeat the 2015 NRE in 2016 & & & 0.49 \\
\hline Yes & $4(2 \%)$ & $5859( \pm 1578)$ & \\
\hline No & $232(98 \%)$ & $5008( \pm 2448)$ & \\
\hline Repeating the NRE at 2015 NRE & & & 0.74 \\
\hline Yes & $23(10 \%)$ & $5181( \pm 2554)$ & \\
\hline No & $213(90 \%)$ & $5006( \pm 2428)$ & \\
\hline Repeated the first year ${ }^{a}$ & & & $<0.0001$ \\
\hline Yes & 89 (57\%) & $5743( \pm 2026)$ & \\
\hline No & $68(43 \%)$ & $3953( \pm 2610)$ & \\
\hline Repetition during university course $\mathrm{e}^{2, a}$ & & & $<0.0001$ \\
\hline Yes & $39(25 \%)$ & $7020( \pm 1705)$ & \\
\hline No & $117(75 \%)$ & $4337( \pm 2283)$ & \\
\hline Gaining a Master's degree (first year) ${ }^{a}$ & & & 0.22 \\
\hline Yes & $31(20 \%)$ & $4523( \pm 2428)$ & \\
\hline No & $125(80 \%)$ & $5128( \pm 2443)$ & \\
\hline Gaining a Master's degree (second year) ${ }^{a}$ & & & 0.44 \\
\hline Yes & $3(2 \%)$ & $3930( \pm 2648)$ & \\
\hline No & $153(98 \%)$ & $5029( \pm 2445)$ & \\
\hline \multicolumn{4}{|l|}{ Attendance at the hospital internship (4th year) ${ }^{a}$} \\
\hline Yes & $156(100 \%)$ & & \\
\hline No & $0(0 \%)$ & & \\
\hline \multicolumn{4}{|l|}{ Attendance at the hospital internship (5th year) ${ }^{a}$} \\
\hline Yes & $156(100 \%)$ & & \\
\hline No & $0(0 \%)$ & & \\
\hline Attendance at the hospital internship (6th year) ${ }^{a, 3}$ & & & $<0.0001$ \\
\hline Yes & $102(65 \%)$ & $5740( \pm 2294)$ & \\
\hline No & $54(35 \%)$ & $3627( \pm 2113)$ & \\
\hline Attendance at the faculty lectures (1st year) $)^{a}$ & & & 0.74 \\
\hline Yes & $148(95 \%)$ & $4980( \pm 2481)$ & \\
\hline No & $7(5 \%)$ & $5300( \pm 1641)$ & \\
\hline Attendance at the faculty lectures (2nd year) ${ }^{a}$ & & & 0.71 \\
\hline Yes & $91(58 \%)$ & $5070( \pm 2389)$ & \\
\hline No & $65(42 \%)$ & $4921( \pm 2535)$ & \\
\hline Attendance at the faculty lectures (3rd year) & & & 0.87 \\
\hline Yes & $77(49 \%)$ & $4974( \pm 2353)$ & \\
\hline No & $79(51 \%)$ & $5041( \pm 2544)$ & \\
\hline
\end{tabular}


Table 1 Description of the categorical variables of the cohort $(n=242)$ and univariate analysis of the predictive factors associated with a better ranking of the Reims students at the 2015 NRE (Continued)

\begin{tabular}{|c|c|c|c|}
\hline Variables & $\mathrm{n}(\%)$ & Mean rank $( \pm \mathrm{SD})$ & $p$ \\
\hline Attendance at the faculty lectures (4th year) ${ }^{a}$ & & & 0.99 \\
\hline Yes & $66(42 \%)$ & $5006( \pm 2412)$ & \\
\hline No & $90(58 \%)$ & $5009( \pm 2481)$ & \\
\hline Attendance at the faculty lectures (5th year) ${ }^{a}$ & & & 0.45 \\
\hline Yes & $58(37 \%)$ & $5006( \pm 2412)$ & \\
\hline No & $98(63 \%)$ & $5009( \pm 2481)$ & \\
\hline Attendance at the faculty lectures (6th year) ${ }^{a}$ & & & 56 \\
\hline Yes & $44(28 \%)$ & $5605( \pm 2277)$ & \\
\hline No & $112(72 \%)$ & $4774( \pm 2477)$ & \\
\hline \multicolumn{4}{|l|}{ Intrinsic motivation ${ }^{a}$} \\
\hline Highly motivated & $74(48 \%)$ & $3664( \pm 2112)$ & $<0.0001$ \\
\hline Moderately motivated & $61(40 \%)$ & $5634( \pm 2016)$ & $<0.0001$ \\
\hline Not motivated & $21(12 \%)$ & $7870( \pm 1078)$ & \\
\hline Extrinsic motivation ${ }^{4, a}$ & & & 0.46 \\
\hline Yes & $28(18 \%)$ & $4692( \pm 2660)$ & \\
\hline No & $127(82 \%)$ & $5067( \pm 2407)$ & \\
\hline Targeted speciality ${ }^{5, a}$ & & & 0.62 \\
\hline Yes & $129(83 \%)$ & $4964( \pm 2403)$ & \\
\hline No & $27(17 \%)$ & $5220( \pm 2667)$ & \\
\hline Targeted city of residency ${ }^{5, a}$ & & & 0.01 \\
\hline Yes & $82(53 \%)$ & $5465( \pm 2444)$ & \\
\hline No & $74(47 \%)$ & $4501( \pm 2358)$ & \\
\hline Personal goal of ranking ${ }^{5, a}$ & $108(46 \%)$ & & \\
\hline
\end{tabular}

${ }^{1}$ All students who are completed the 2015 NRE. SD: standard-déviation. ${ }^{2}$ First and sixth years excluded. ${ }^{3}$ Motivation were in $100 \%$ of cases, revision and preparation of the NRE. ${ }^{4}$ Exstrinsic motivation that means the student feeling about their faculty supports in the NRE preparation and/or learning their future profession. ${ }^{5}$ Before completed the 2015 NRE. ${ }^{a}$ Unknown: $n=80$ (33\%); ${ }^{b}$ Unknown: $n=50$ (21\%); ${ }^{\text {CUnknown: }} n=59$ (25\%)

boldface entries are statistically significant with a $p<0.05$

\section{Discussion}

The results of this study demonstrate for the first time that strong student motivation is independently and significantly associated with a gain of places at the NRE (average of 3327 places). While these results are in agreement with literature data in that a high level of intrinsic motivation often correlates with better exam success, none of the studies investigating predictive factors for NRE success previously published had shown this correlation [10-12]. Nevertheless, in 2015 Agrinier et al., showed that there was a tendency to gain places when intrinsic and extrinsic motivations was high, but their results were not confirmed in multivariate analysis [13]. Intrinsic motivation (defined as the driving force for the realization of an act from which the individual derives pleasure or satisfaction [14]) of the student was measured by a Likert-scale self-survey developed for this study. The students were overwhelmingly (88\%) intrinsically motivated in their preparation for the NRE. This data seems in agreement with most previously published literature [11]. Indeed, Sobral showed in 2004 that the motivational profile of medical students was strongly self-determined and that the degree of intrinsic motivation was high [11]. However, the extrinsic motivation represented by faculty supports was low, only $18 \%$ of the surveyed students (66\% of the 2015 cohort) felt supported or motivated by their faculty for NRE preparation but also for learning their future professional skills. Although this assessment by the student is, like the motivation, subjective, it is nevertheless very informative because $100 \%$ of the students questioned presented no difficulty for giving an answer and $100 \%$ of the answers were either affirmative or negative. The results of this study made from the 2015 class corroborate student feelings from previous and subsequent years in this medical school $[15,16]$. The perception of failure by the medical students at this medical school is partly based on a non-controllable external factors such as, for example, the lack of teachers' supervision, the examination conditions or difficulties making them resort to 
Table 2 Description of categorical variables in the cohort $(n=242)$ and univariate analysis of predictive factors, relating to training conferences and national white NRE participation, associated with a better rank of the Reims students at 2015 NRE

\begin{tabular}{|c|c|c|c|}
\hline Variables & $\mathrm{n}(\%)$ & Mean rank ( \pm SD) & $p$ \\
\hline Enrolled in free training conferences organized by the author & & & 0.04 \\
\hline Yes & $126(53 \%)$ & $4725( \pm 2309)$ & \\
\hline No & $110(47 \%)$ & $5365( \pm 2541)$ & \\
\hline$\geq 1$ lecture & & & 0.14 \\
\hline Yes & $122(52 \%)$ & $4791( \pm 2279)$ & \\
\hline No & $111(48 \%)$ & $5264( \pm 2590)$ & \\
\hline$\geq 3$ lectures & & & 0.57 \\
\hline Yes & $75(33 \%)$ & $4899( \pm 2268)$ & \\
\hline No & $154(67 \%)$ & $5093( \pm 2522)$ & \\
\hline$\geq 15$ lectures & & & 0.44 \\
\hline Yes & $20(9 \%)$ & $4622( \pm 2279)$ & \\
\hline No & $212(91 \%)$ & $5067( \pm 2452)$ & \\
\hline$\geq 25$ lectures & & & 0.33 \\
\hline Yes & $5(2 \%)$ & $6075( \pm 1458)$ & \\
\hline No & $227(98 \%)$ & $5006( \pm 2450)$ & \\
\hline \multicolumn{4}{|l|}{ All the lectures $(n=30)$} \\
\hline Yes & $0(0 \%)$ & & \\
\hline No & $236(100 \%)$ & & \\
\hline Enrolled in paying training conferences organized by the Reims medical school (FERM ${ }^{1}$ ) & & & 0.37 \\
\hline Yes & $172(73 \%)$ & $4936( \pm 2436)$ & \\
\hline No & $64(27 \%)$ & $5257( \pm 2438)$ & \\
\hline$\geq 1$ lecture & & & 0.53 \\
\hline Yes & $119(77 \%)$ & $4927( \pm 2349)$ & \\
\hline No & $36(23 \%)$ & $5220( \pm 2770)$ & \\
\hline$\geq 3$ lectures & & & 0.41 \\
\hline Yes & $108(70 \%)$ & $4889( \pm 2287)$ & \\
\hline No & $47(30 \%)$ & $5237( \pm 2789)$ & \\
\hline All the lectures & & & 0.054 \\
\hline Yes & $36(23 \%)$ & $4307( \pm 2254)$ & \\
\hline No & 119 (77\%) & $5203( \pm 2473)$ & \\
\hline \multicolumn{4}{|l|}{ Paid private training conferences (4th year) ${ }^{a}$} \\
\hline Yes & $1(0,6 \%)$ & 4518 & \\
\hline No & $155(99,4 \%)$ & $5011( \pm 2452)$ & \\
\hline Paid private training conferences $\left(5\right.$ th year) ${ }^{a}$ & & & 0.03 \\
\hline Yes & $56(36 \%)$ & $4424( \pm 2420)$ & \\
\hline No & $100(64 \%)$ & $5335( \pm 2408)$ & \\
\hline Paid private training conferences (6th year) ${ }^{a}$ & & & 0.17 \\
\hline Yes & $109(70 \%)$ & $4830( \pm 2332)$ & \\
\hline No & 47 (30\%) & $5419( \pm 2667)$ & \\
\hline Hermès conference ${ }^{2}$ & & & 0.006 \\
\hline Yes & $63(41 \%)$ & $4389( \pm 2263)$ & \\
\hline No & $92(59 \%)$ & $5472( \pm 2461)$ & \\
\hline Hippocrate conference ${ }^{3}$ & & & 0.26 \\
\hline
\end{tabular}


Table 2 Description of categorical variables in the cohort $(n=242)$ and univariate analysis of predictive factors, relating to training conferences and national white NRE participation, associated with a better rank of the Reims students at 2015 NRE (Continued)

\begin{tabular}{|c|c|c|c|}
\hline Variables & n (\%) & Mean rank ( \pm SD) & $p$ \\
\hline Yes & $2(1 \%)$ & $6946( \pm 1833)$ & \\
\hline No & $153(99 \%)$ & $5006( \pm 2436)$ & \\
\hline Conf + conference ${ }^{4}$ & & & 0.75 \\
\hline Yes & $30(19 \%)$ & $5157( \pm 2226)$ & \\
\hline No & $125(81 \%)$ & $5001( \pm 2489)$ & \\
\hline Khalifa conference ${ }^{5}$ & & & 0.74 \\
\hline Yes & $6(4 \%)$ & $5363( \pm 2345)$ & \\
\hline No & 149 (96\%) & $5018( \pm 2444)$ & \\
\hline Raphael conference ${ }^{6}$ & & & 0.92 \\
\hline Yes & $11(7 \%)$ & $5175( \pm 2976)$ & \\
\hline No & $137(93 \%)$ & $5103( \pm 2346)$ & \\
\hline White NRE (4th year) $)^{a}$ & & & 0.61 \\
\hline Yes & $2(1 \%)$ & $4125( \pm 4045)$ & \\
\hline No & $154(99 \%)$ & $5019( \pm 2436)$ & \\
\hline White NRE (5th year) ${ }^{a}$ & & & 0.007 \\
\hline Yes & $33(21 \%)$ & $3995( \pm 2360)$ & \\
\hline No & $123(89 \%)$ & $5280( \pm 2403)$ & \\
\hline White NRE (6th year) ${ }^{a}$ & & & 0.0001 \\
\hline Yes & $134(86 \%)$ & $4709( \pm 2372)$ & \\
\hline No & $22(14 \%)$ & $6829( \pm 2100)$ & \\
\hline Revue du praticien November $2014^{7, a}$ & & & $<0.0001$ \\
\hline Yes & $103(67 \%)$ & $4399( \pm 2379)$ & \\
\hline No & $50(33 \%)$ & $6334( \pm 2038)$ & \\
\hline Hippocrate January 20153,b & & & 0.24 \\
\hline Yes & $104(56 \%)$ & $4876( \pm 2302)$ & \\
\hline No & $82(44 \%)$ & $5305( \pm 2602)$ & \\
\hline Revue du praticien March 2015 & & & $<0.0001$ \\
\hline Yes & $107(69 \%)$ & $4430( \pm 2346)$ & \\
\hline No & 47 (31\%) & $6309( \pm 2213)$ & \\
\hline Hippocrate March $2015^{3, c}$ & & & 0.004 \\
\hline Yes & $73(41 \%)$ & $4230( \pm 2540)$ & \\
\hline No & $104(59 \%)$ & $5325( \pm 2391)$ & \\
\hline
\end{tabular}

${ }^{1}$ Association of federation for the Reims medical students (FERM). ${ }^{2}$ Hermès conference, SASU, 11 rue de la vistule, Paris. ${ }^{3}$ Hippocrate-ECN conference, Faculté Dauphine, Place du Maréchal de Lattre de Tassigny, Paris. ${ }^{4}$ Med XL (Conf + conference), 15 Rue Saint Bernard, Paris. ${ }^{5}$ Khalifa conference, Établissement d'enseignement supérieur libre, 134 Rue de Grenelle, Paris. ${ }^{6}$ Conf-raphael conference, 10 rue Castex, Paris. ${ }^{7}$ ECN-blanches la Revue du Praticien conference, Global Média Santé, 314, Bureau de la Colline, Saint-Cloud Cedex. ${ }^{a}$ Unknown: $n=80$ (33\%); ${ }^{b}$ Unknown: $n=50$ (21\%); ${ }^{C}$ Unknown: $n=59$ (25\%)

boldface entries are statistically significant with a $p<0.05$

failure avoidance behaviours such as defensive pessimism, that is well known, depreciates intrinsic motivation $[15,17,18,19]$. Nevertheless, despite a low extrinsic motivation represented mainly by the perception of a low motivational support on the part of the faculties, the students were mainly very motivated. However, it seems legitimate to assume that an increase in motivational support by faculties would reinforce the extrinsic motivation and inevitably increase the intrinsic self-motivation of the students, thus positively influencing their level of investment and their perseverance during NRE preparation. This could be an interesting and viable outcome strategy to improve the average rank of all students of this medical school at the national level.

This study also demonstrates for the second time, both independently and statistically, that the students NRE preparation by their participation in the national NRE white tests organized by private organizations is associated 
Table 3 Description of the quantitative variables of the population $(n=242)$ and univariate analysis of the predictive factors associated with a better ranking of the Reims students at the 2015 NRE

\begin{tabular}{|c|c|c|c|c|}
\hline$\underline{\text { Variables }}$ & $\mathrm{n}$ & Mean rank $( \pm S D)$ & $r^{d}$ & $p$ \\
\hline Mean age (year) & 242 & $25.2( \pm 1.5)$ & 0.41 & $<0.0001$ \\
\hline Mean rank in first year ${ }^{1}$ & 207 & $122( \pm 73)$ & 0.29 & $<0.0001$ \\
\hline Mean results at the $\mathrm{CSCT}^{2}$ (in points) & 230 & $573( \pm 67)$ & -0.80 & $<0.0001$ \\
\hline Mean rank (SD) at the $\mathrm{CSCT}^{2}$ & 230 & $116( \pm 67)$ & 0.80 & $<0.0001$ \\
\hline \multicolumn{5}{|l|}{ White NRE (sixth year) ${ }^{a}$} \\
\hline Median number of white NRE completed ${ }^{a}$ & 156 & 3 (range: 0-6) & -0.44 & $<0.0001$ \\
\hline Mean results at Hippocrate white NRE January $2015^{3, b}$ & 97 & $449( \pm 101)$ & -0.73 & $<0.0001$ \\
\hline Mean rank at Hippocrate white NRE January $2015^{3, b}$ & 97 & $2699( \pm 1023)$ & 0.79 & $<0.0001$ \\
\hline Mean results at Hippocrate white NRE March $2015^{3, c}$ & 63 & $557( \pm 123)$ & -0.79 & $<0.0001$ \\
\hline Mean results at Hippocrate white NRE March 2015 3,c & 63 & $1812( \pm 1053)$ & 0.75 & $<0.0001$ \\
\hline
\end{tabular}

${ }^{1}$ One student entered the second cycle of medical studies with a counter-equivalence and did not attend the first year ranking exam. SD: standard-deviation. ${ }^{2}$ CSCT: French certificate of clinical synthesis and therapeutics. ${ }^{3}$ Hippocrate-ECN conference, Faculté Dauphine, Place du Maréchal de Lattre de Tassigny, Paris. a Unknown: $n=80$ (33\%); ${ }^{b}$ Unknown: $n=50(21 \%) ;{ }^{c}$ Unknown: $n=59(25 \%)$. ${ }^{d}$ a negative correlation coefficient $r$ was associated with a better ranking

boldface entries are statistically significant with a $\mathrm{p}<0.05$

with an average gain of more than 600 places. Indeed, in 2010 Andujar et al., demonstrated that the participation in the NRE white tests was independently and significantly associated with a better rank at the NRE [12]. In 2015, Le Rouzic et al., demonstrated that participation in the NRE white test was significantly associated with a better ranking with a dose-effect relationship in the absence of adjustment for confounding factors [20]. While participation at the NRE white test has a positive impact on the NRE student ranking, attendance of the NRE training conferences, whether public or private, free or paid, was not independently and significantly associated with gain or loss of NRE places in multivariate analysis in this previous study [20]. Several hypotheses can be formulated to explain these results. Ninety-four percent of the students had attended a NRE training conferences during

Table 4 Multivariate analysis of the predictive factors associated with a better rank of the Reims students at 2015 NRE

\begin{tabular}{|c|c|c|c|}
\hline Variables & $\beta \pm S E$ & IC $95 \%$ & $p$ \\
\hline Age & $-225 \pm 114$ places & {$[-450 ; 0,28]$} & 0.0503 \\
\hline Repeated the first year ${ }^{a}$ & $-1410 \pm 286$ places & {$[-1976 ;-844]$} & $<0.0001$ \\
\hline Repetition during university course $\mathrm{e}^{1, a}$ & $-1092 \pm 385$ places & {$[-1853 ;-331]$} & 0.005 \\
\hline Enrolled in free training conferences organized by the author & $-281 \pm 303$ places & {$[-880 ; 317]$} & 0.35 \\
\hline Paid private training conferences (5th year) ${ }^{a}$ & $+44 \pm 354$ places & {$[-880 ; 317]$} & 0.9 \\
\hline Paid private training conferences (6th year) ${ }^{a}$ & $-249 \pm 373$ places & {$[-987 ; 489]$} & 0.5 \\
\hline Hermès conference ${ }^{2}$ & $+148 \pm 348$ places & {$[-539 ; 836]$} & 0.50 \\
\hline White NRE in 5 th $^{\text {year }}{ }^{\mathrm{a}}$ & $-371 \pm 410$ places & {$[-1184 ; 442]$} & 0.36 \\
\hline White NRE in 6th year ${ }^{\mathrm{a}}$ & $-850 \pm 536$ places & {$[-1909 ; 210]$} & 0.12 \\
\hline Revue du Praticien November 2014,a & $+869 \pm 425$ places & {$[27 ; 1711]$} & 0.04 \\
\hline Revue du Praticien March 2015 3,a & $+61 \pm 430$ places & {$[-790 ; 912]$} & 0.88 \\
\hline Hippocrate mars $2015^{4, c}$ & +613 \pm 297 places & {$[26 ; 1200]$} & 0.04 \\
\hline Attendance of hospital internship (6th year) ${ }^{a}$ & $-706 \pm 298$ places & {$[-1297 ;-116]$} & 0.02 \\
\hline \multicolumn{4}{|l|}{ Intrinsic motivation ${ }^{10, a}$} \\
\hline Highly motivated & + $3327 \pm 527$ places & {$[2284 ; 4370]$} & $<0.0001$ \\
\hline Moderately motivated & + $1905 \pm 474$ places & {$[968 ; 2842]$} & $<0.0001$ \\
\hline Not motivated & reference & & \\
\hline Targeted city of residency ${ }^{12, a}$ & $-255 \pm 281$ places & {$[-810 ; 300]$} & 0.36 \\
\hline
\end{tabular}




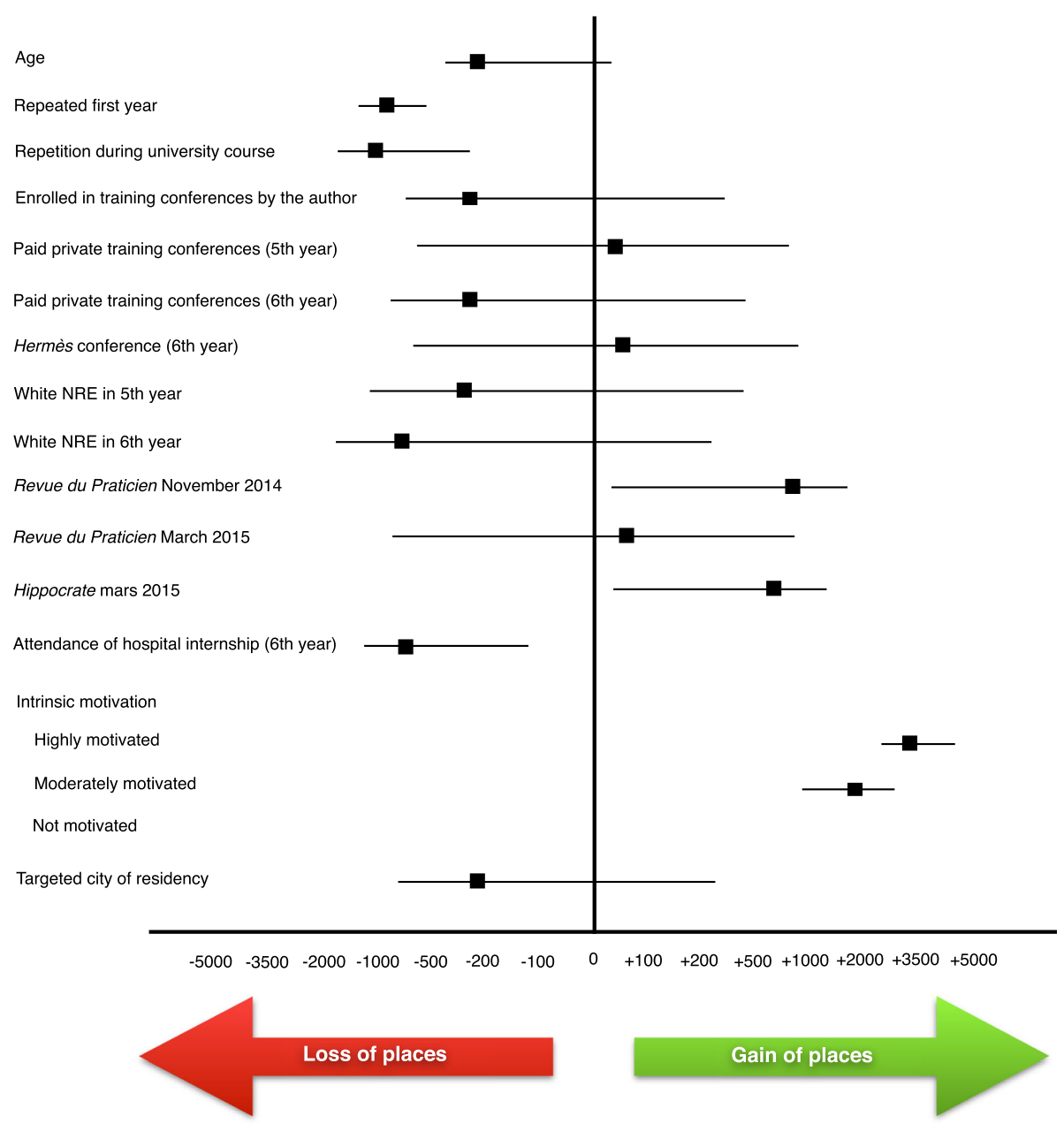

Fig. 2 Forest plot of predictive factors associated with a better ranking of the Reims medical school students at 2015 NRE from the multivariate analysis

their 6th year, which severely limits the possibilities of comparison. Indeed, the vast majority of students want to give themselves every opportunity to succeed and therefore enroll in these NRE training conferences whether public or private. Nevertheless, it appears that students who have completed a NRE training conference in their 5th year have gained NRE places, but these significant results in univariate analysis have not been confirmed in the multivariate model. As well as, the students who followed the NRE training conference by Hermès (Conference Hermès, SASU, 11 rue de la vistule, Paris) in their 6th year had a significant gain in places compared to other students, but these results have not been confirmed in the multivariate model. A literature search seems contradictory about the impact of the NRE training conferences on the final NRE student rank. In 2011, Karila et al., did not demonstrate that regular attendance at medical school conferences was significantly and independently associated with a top-500 ranking at the ECN in multivariate analysis, although it appeared that this was the case in univariate analysis [10]. In 2015, Agrinier et al. reported that attendance of NRE training conferences was significantly and independently associated with an average gain of 873 NRE places with a dose-effect relationship of 63 places per conference attended [13]. More recently, in a study of predictive factors for success at the 2017 computerized-NRE and presented at the 76th congress of the French National Society of Internal Medicine (SNFMI), Bellamine et al., demonstrated that participation in training conferences organized by the medical school is significantly and independently associated with success at the computerized-NRE [21].

Our study also demonstrates for the first time that the 6th year hospital internships attendance was associated independently and significantly with an average loss of 706 NRE places. At the school of medicine of Reims, the hospital students (from the 4th to the 6th year) alternate 6 weeks periods of daily lectures (whole days) with university tests at the end of these last ones and 6 weeks periods of full-time hospital internships. Hospital 


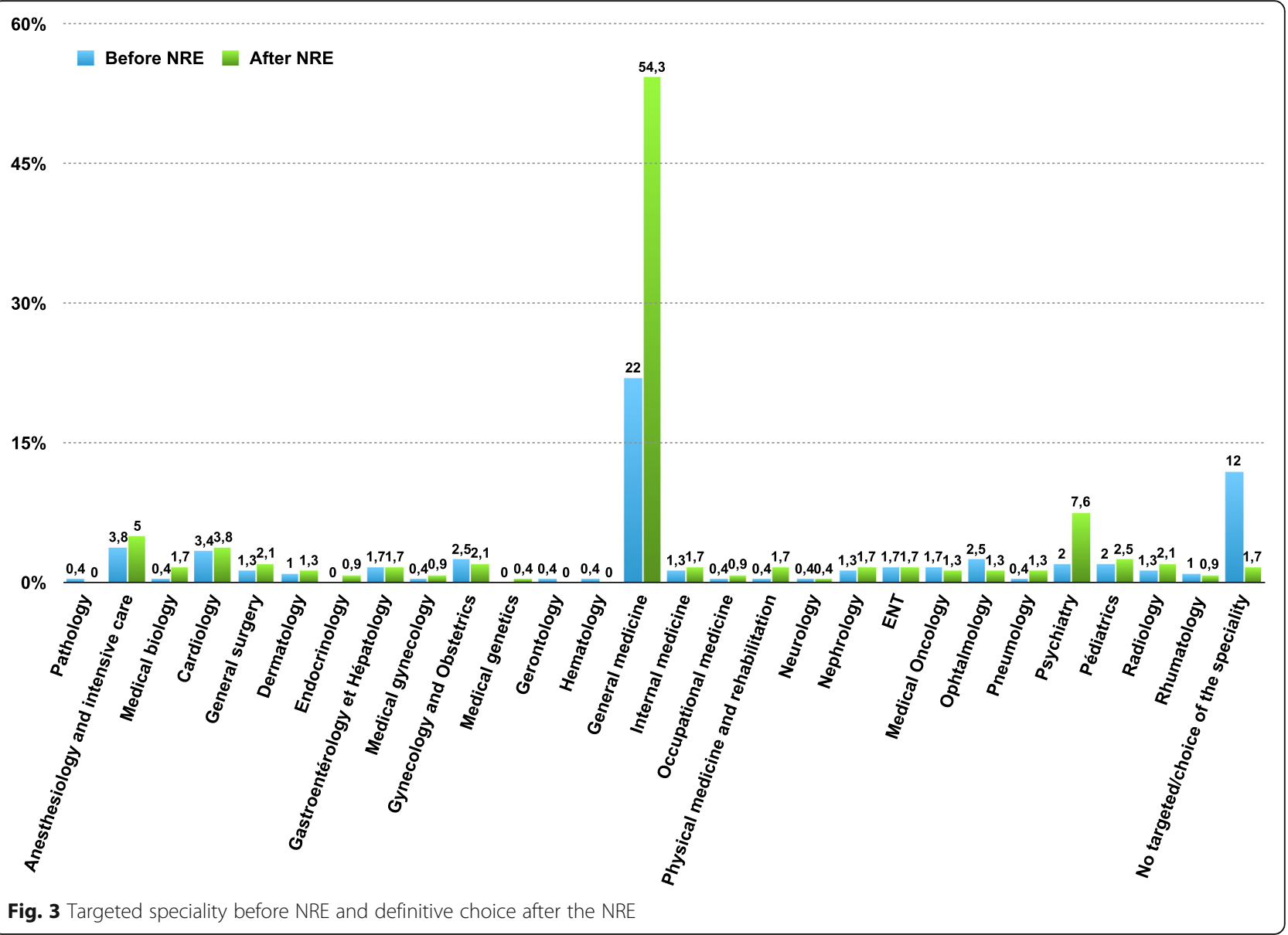

internships are not being coordinated and correlated to the themes of the previous weeks of lectures. In the 6th year of medical studies, the hospital internships take place over 3 months with attendance only in the morning, the afternoon being reserved for lectures. Although mandatory and within the compulsory framework of the 6th year, the tolerance of the faculties-supervisors about the time of attendance in hospital internships for the students is not uniform across medical schools, or even within the same medical school [2]. Some have set up revision periods of varying durations (usually 1 month) by shifting the hospital internships after the NRE [2]. In this study, 35\% of students surveyed (66\% of the 2015 NRE) reported that they attended less than $50 \%$ of the time required during their 6th year clinical internship and were better ranked at the NRE. The reason for their absence was in $100 \%$ of cases for revision and preparation for the NRE. This result leads to several reflections, on the one hand because the acquisition of the whole second cycle program is truely daunting (345 items) and requires some "free" time wholely devoted to in depth learning. Indeed, it is illusory to believe that medicine could be learned entirely at the patient's bedside or simply replace personal book work in favor of clinical internships. On the other hand, because the acquisition of the second cycle program is the minimum required for the exercise of quality medicine. The necessary exercise of consolidation of the six university years that it imposes represents a real test of intellectual endurance incompatible with a daily appearance on the hospital wards. In other words, the 6th year medical student probably does not take advantage of the bedside teaching in an optimal way and probably sacrifice precious revision time, and this study underlines that the organization of the working time of the students is critical to their success at NRE. In 2015, Gillois et al., demonstrated that integrated university-hospital training programs that coincide with faculty courses over time could provide a successful way for improving student success at NRE [22]. In addition, the results of the Agrinier et al. in 2015 seems to corroborate the results of our study [13].

Finally, this study confirms that the fact of having repeated the first year but also repeating during the university course (independently of the first year) was independently and significantly associated with an average loss of more than 1000 places at the NRE. Indeed, previous studies have also demonstrated this state of affairs [10, 12, 13, 22, 23].

The decree of the 20th July 2015 about the organization of the NRE leading to the third cycle of medical studies 


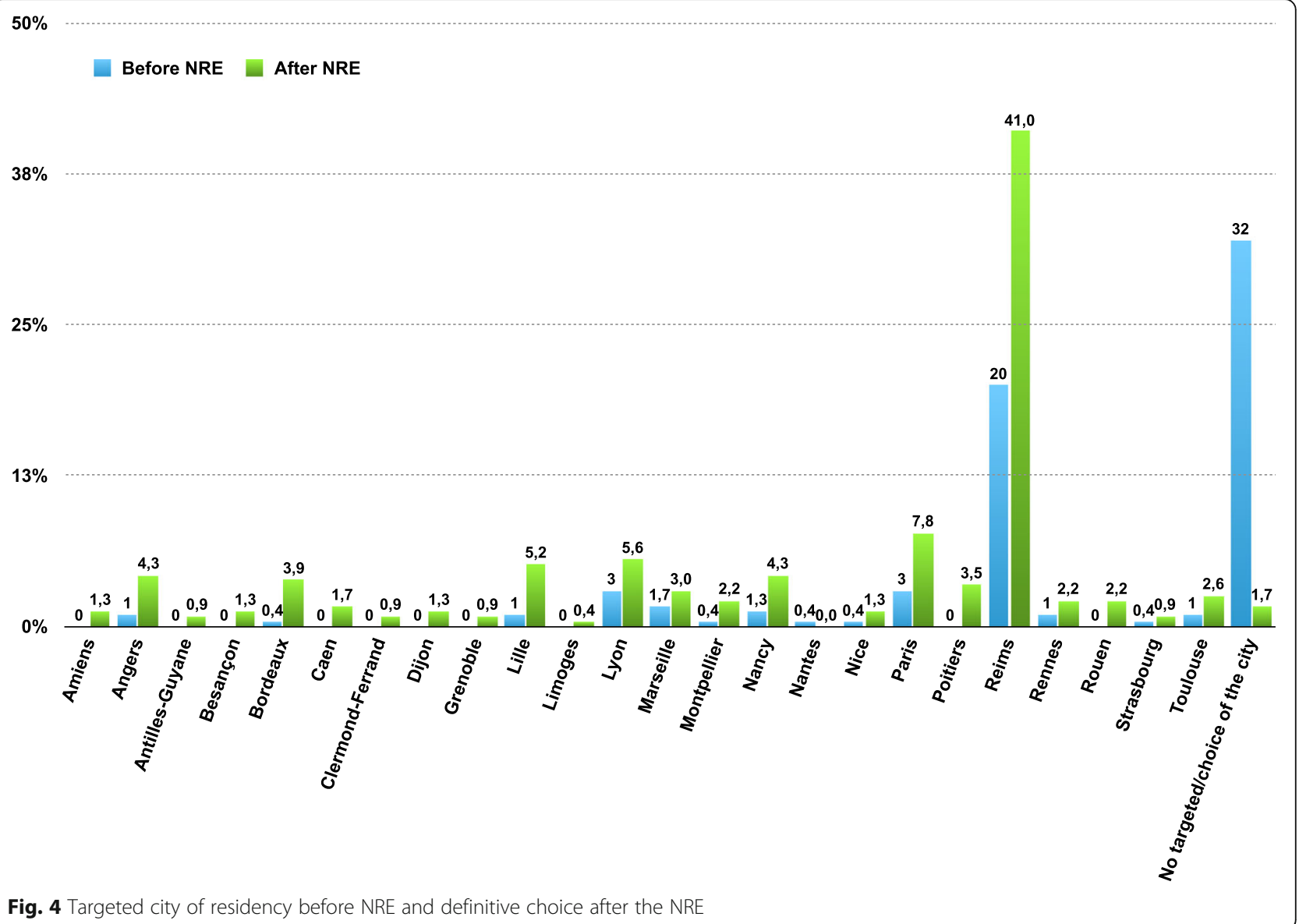

(residency) has transformed this examination since 2004 and it has now evolved into a computerized format called NREc (ECNi) set up in 2016. While the initial desire for such a reform was to overcome the NRE which was judged: $1 /$ Non-discriminatory due to the increase of the numerus clausus and the increasing number of medical students; 2/ Too cumbersome logistically, in manpower and cost; 3 / Of a limited educational value, favoring the excess of "cramming" focused on factual memorization [24], the first feedbacks do not seem to meet the objectives set [25] and the setbacks of the 2017 NREc events strongly questioned the value of these change [26]. Even though the reform of the medical residency competition with the implementation of the NRE in 2004 and the change of format that it implied did not change the profile of the wellranked student $[10,23]$. It is possible, it will be necessary to verify it, that the evolution of the NRE towards a computerized form, including also the change of testing format, will not affect the profile of the well-ranked student. Moreover, this seems to be confirmed by the recent work of Bellamine et al. [21]. Thus, it is clear that the profile of the well-ranked student in the medical residency competition before 2004, the NRE from 2004 to 2015 and the
NREc from 2016 to today remains the same. While digitization and computing are great tools and they provide many educational services, they are still tools that serve the teacher and fortunately we cannot yet replace them.

This study has several limitations, the first one is related to its retrospective nature and the fact that students filled in a self-survey that could have a memory bias. The second one is that the response rate to the self-survey represents $66 \%$ of the 2015 NRE cohort of the medical school studied. Nevertheless, the study of the judgment criterion (NRE rank) of respondents to the survey against nonresponders is almost identical, which makes it reasonable to assume that the sample surveyed seems representative of the entire student population. The third one is that the measurement of student motivation was performed by a 3-items Likert-scale. Taking into account the inherently subjective nature of this measure, it corresponds in practice to a decision that is easily expressed by students. This measure is certainly methodologically questionable, but nevertheless it has the advantage of being a very easy collected objective data by the students themselves. In addition, it could be interesting to explore the grit factor, 
or the perseverance and passion for long-term goals, which is a personality trait that is described as persevering through difficult tasks [27]. Indeed, recent reports showed that grit is a powerful predictor of medical student success [28-30]. Finally, this study considered only predictive factors for students themselves (exam success, attendance at lectures, attendance at hospital internships, participation in white NRE examination or hopeful selection of specialty, city, etc.). It would be useful objectively to determine the direct impact of the lectures (of their quality, their number or their intensity) on the rank of NRE, but such a study seems difficult to put in place. Nevertheless, many relevant indicators, albeit indirect ones, reflect the quality of medical school teaching, which seems to be the most important factor, consistent and everlasting in the success of the students at the NRE $[3,10,31]$.

\section{Conclusions}

The results of this study confirm that most medical students are highly motivated and invest in learning for their future profession. The external validity of this study shows that the profile of the "well-ranked" student is relatively stereotyped, reproducible and seems insensitive to the variables of time and place (medical school of origin). However, as suggested by the results of this study, all factors improving positively the student motivation in the preparation of the NRE should be highly considered as it was a huge prognostic factor of NRE success. In this way, considering to increase the number of white test examinations, decrease the time of attendance of hospital internship within the year of NRE associated to an improvement of extrinsic student motivation from faculty should be an interesting way to increase the intrinsic student motivation and the national rank of the medical school of Reims, but probably more broadly to all medical school. It would now be relevant to carry out other studies aimed at evaluating the impact of teaching methods and tools, but also the investment, motivation and profile of teachers from various medical schools to determine whether these factors influence the results of medical students at NRE and see if in the long-term they might allow to train more independent and competent young doctors.

\section{Supplementary information}

Supplementary information accompanies this paper at https://doi.org/10. 1186/s12909-019-1903-5.

Additional file 1. Survey items

\section{Abbreviations}

FERM: Federation for Reims medical students association; NRE: National ranking examination

Acknowledgements

Not applicable.

\section{Authors' contributions}

All persons listed as authors have contributed substantially to the design, performance, analysis, and reporting of this work. ML, MH, TL, QM, VH: collected data, analyzed data, wrote paper. ML, MD: analyzed data, performed statistical analysis, wrote paper. ML, PH, LL, DS: Designed study, analyzed data, wrote paper. All authors read and approved the final manuscript.

\section{Funding}

No funding was obtained for this study.

\section{Availability of data and materials}

The datasets that support the findings of this study are available from the corresponding author upon reasonable request.

\section{Ethics approval and consent to participate}

This study was declared and approved by the French National Commission of Informatics and Liberties (CNIL n'1907841v0) according to the French laws. Students consented to participate through completion of the survey form of the study. They were excluded from the study if they refused to participate.

\section{Consent for publication}

Not applicable.

\section{Competing interests}

$T L$ was a teacher at the Hippocrate private training conference (HippocrateECN, Faculté Dauphine, Place du Maréchal de Lattre de Tassigny, Paris) during university years 2015-2016. QM was a teacher at the Medical School of Reims for the federation for Reims medical students association (FERM) during the university years 2013-2015. VH was a teacher at the Hermès private training conference (Conférence Hermès, SASU, 11 rue de la vistule, Paris) from 2009 to 2013

\section{Author details}

'Department of General and Digestive Surgery, Hôpital Robert Debré, Centre Hospitalier Universitaire de Reims, Université de Reims Champagne-Ardenne, Avenue du Général Koenig, 51092 Reims, France. '2Department of Plastic, Reconstructive and Aesthetic Surgery, Hôpital Européen Georges Pompidou, Assistance Publique des Hôpitaux de Paris, Université Paris Descartes, Paris, France. ${ }^{3}$ Department of Research, Innovation and Biostatistics, Hôpital Pierre Zodba-Quitman, Centre Hospitalier Universitaire de Martinique, Université des Antilles, Fort de France, Martinique, France. ${ }^{4}$ Department of Cardiology, Hôpital Robert Debré, Centre Hospitalier Universitaire de Reims, Université de Reims Champagne-Ardenne, Reims, France. ${ }^{5}$ Department of Intensive Care Unit, Hôpital de Hautepierre, Université de Strasbourg, Strasbourg, France. ${ }^{6}$ Institute of Anatomy and Clinical Education, Warwick Medical School, University of Warwick, Coventry CV4 7AL, UK.

Received: 27 April 2019 Accepted: 9 December 2019

Published online: 21 December 2019

References

1. Duhaut P. National ranking examination four years after its implementation: thoughts. Rev Med Interne. 2008;29(7):531-4.

2. Grosbois B. [Results of French medical students' ranking exam: The quest for the Holy Grail for students... and medical faculties?]. Rev Med Interne 2011; 32(7):397-399.

3. Rabineau D, Dhainaut JF. First steps towards a comparative evaluation of the French medical schools. Presse Med. 2010;39(1):e1-10.

4. Jolly D, Ambrosi P, Chaffanjon P, Dreyfuss D, Le Jeunne C, Lorette G, et al. Results of the 2015 national ranking in France. Presse Med. 2016;45(1):133-42

5. Jolly D, Lorette G, Ambrosi P, Dreyfuss D, Magne JL, Kohler C, et al. 2010 National Ranking in France: results, classifications, consequences of critical appraisal of medical literature. Presse Med. 2011;40(4 Pt 1):447-8.

6. Jolly D, Lorette G, Ambrosi P, Dreyfuss D, Chaffanjon P, Kohler C, et al. Results of the 2011 national ranking in France. Presse Med. 2012;41(3 Pt 1):323-5. 
7. Jolly D, Lorette G, Ambrosi P, Dreyfuss D, Chaffanjon P, Le Jeunne C, et al. Results of the 2012 national ranking in France. Presse Med. 2013;42(7-8):1138-40.

8. Jolly D, Ambrosi P, Chaffanjon P, Dreyfuss D, Le Jeunne C, Lorette G, et al. Results of the 2013 national ranking in France. Presse Med. 2014:43(7-8):865-7.

9. Jolly D, Ambrosi P, Chaffanjon P, Dreyfuss D, Le Jeunne C, Lorette $G$, et al. Results of the 2014 national ranking in France. Presse Med. 2015;44(5):533-5.

10. Karila L, Seringe E, Roupret M, Peltier M, Doulaki M, Goumont M, et al. Which are the predictive factors to be ranked within the 500 first medical students at the national ranking exam? A cross-sectional study of the 2009 class. Rev Med Interne. 2011;32(7):400-5.

11. Sobral DT. What kind of motivation drives medical students' learning quests? Med Educ. 2004;38(9):950-7.

12. Andujar P, Bastuji-Garin S, Botterel F, Prevel M, Farcet JP, Claudepierre P. Factors affecting students performance on the National Ranking Examination in a French medical school. Presse Med. 2010;39(6):e134-40.

13. Agrinier N, Bannay A, Santini J, Braun M, Angioi K, Debouverie M, et al. Impact of training conferences on medical student's performance for the French National Ranking Examination in Lorraine University. The ETIMCEL experimental study. Rev Med Interne. 2015;36(2):78-88.

14. Deci $E$, Ryan R. Intrinsic motivation and self-determination in human behavior. New York: Editions Plenum Press; 1985

15. Frey C. La faculté de Médecine de Reims avant-dernière de France. L'Union; 2016

16. Frey C. Reims : les étudiants en médecine répondent à leur doyen. L'Union; 2016

17. Frey C. Le doyen de médecine explique les mauvais résultats de sa faculté L'Union; 2016.

18. Pelaccia T, Delplancq H, Triby E, Leman C, Bartier J-C, Dupeyron J-P. La motivation en formation : une dimension réhabilitée dans un environnement d'apprentissage en mutation. Pédagog Méd. 2008;9(2):103-21.

19. Deci EL, Koestner R, Ryan RM. A meta-analytic review of experiments examining the effects of extrinsic rewards on intrinsic motivation. Psychol Bull. 1999:125(6):627-68 discussion 92-700.

20. Le Rouzic O, Gosset D, Dharancy S, Lacroix D, Truffert P. Participation in internship conferences improves the ranking position in French nationa ranking exam. Presse Med. 2015;44(9):943-4.

21. Bellamine A, Leccas A, Renaud MC, Aubart FC, Steichen O, Lefevre J, et al. Classement aux epreuves classantes nationales informatisées (ECNi) 2017 : facteurs associés à la réussite et à la non-réussite à partir de données longitudinales de la scolarité. La Rev de Méd Interne 2017;38:A101-A1A2.

22. Gillois P, Fourcot M, Genty C, Morand P, Bosson JL. The keys to success in French medical National Ranking Examination: integrated training activities in teaching hospital and medical school. Presse Med. 2015;44(12 Pt 1):e353-61.

23. Thuret $\mathrm{G}$, Brouillet É, Gain P. Analyse multivariée des facteurs de réussite à l'ancien concours d'internat en médecine. Presse Med. 2005;34(11):781-5.

24. ECNi : Groupe de Travail Interministériel. Les Épreuves Classantes Nationales Informatisées. Modernisation des Épreuves Classantes Nationales. Étude de faisabilité pédagogique. http://side-sante.org/?q=node/4. Accessed 3 May 2014; viewed in March 24th 2018

25. Roux D, Meyer G, Cymbalista F, Bouaziz JD, Falgarone G, Tesniere A, et al. Computerized ranking test in three French universities: staff experience and students' feedback. Rev Med Interne. 2016;37(3):166-72.

26. Rhodes M. Jean-Luc Dubois-Randé : "Il faut sortir du tout ECN". EducPros by L'Étudiant. 1 Septembre 2017.

27. Duckworth AL, Peterson C, Matthews MD, Kelly DR. Grit: perseverance and passion for long-term goals. J Pers Soc Psychol. 2007;92(6):1087-101.

28. Salles A, Lin D, Liebert C, Esquivel M, Lau JN, Greco RS, et al. Grit as a predictor of risk of attrition in surgical residency. Am J Surg. 2017;213(2):288-91.

29. Miller-Matero LR, Martinez S, MacLean L, Yaremchuk K, Ko AB. Grit: A predictor of medical student performance. Educ Health (Abingdon, England). 2018;31(2):109-13.

30. Cortez AR, Winer LK, Kim Y, Hanseman DJ, Athota KP, Quillin RC 3rd Predictors of medical student success on the surgery clerkship. Am J Surg. 2019;217(1):169-74.
31. Riviere E, Quinton A, Roux X, Boyer A, Delas H, Bernard C, et al. Choice of career by French medical students after the national ranking exam in 2012. Presse Med. 2013;42(12):e417-24.

\section{Publisher's Note}

Springer Nature remains neutral with regard to jurisdictional claims in published maps and institutional affiliations.
Ready to submit your research? Choose BMC and benefit from:

- fast, convenient online submission

- thorough peer review by experienced researchers in your field

- rapid publication on acceptance

- support for research data, including large and complex data types

- gold Open Access which fosters wider collaboration and increased citations

- maximum visibility for your research: over $100 \mathrm{M}$ website views per year

At BMC, research is always in progress.

Learn more biomedcentral.com/submissions 